\title{
Self-Evaluation; or, How Good Is My Library?
}

Mr. Carnovsky is associate professor, Graduate Library School, University of Chicago. This paper is based upon an informal talk before the Junior College $\mathrm{Li}$ braries Section of the Association of College and Reference Libraries, December 30, 1941 .

Colleges have conventionally been evaluated in terms of certain static elements: the amount of income, the number of Ph.D.'s on the staff, the number of books in the library, etc. However, within more recent years there has been evident a tendency to judge a college primarily in terms of its ability to accomplish its designated goals. The particular kind of education it undertakes to provide and its methods of providing it are basic considerations rather than the units of the program seen in isolation from the educational achievement. Only as these elements or units can be shown to bear a significant relationship to the nature and quality of the educational product are they important in an assessment of the institution.

In the light of this general principle it is clear that a college library is good or not in the degree to which it is equipped to aid in achieving the aims of the college. The ownership of so many books and periodicals, the spending of so much money, the employment of so many persons to help administer the library-none of these bears directly on the central question of the relation of a library to its college. Nevertheless, these and other factors do represent the more tangible elements in library performance, either directly or in a contributory sense; therefore they are proper approaches to the basic question, How good is my library?

\section{Six Factors in Evaluation}

Accrediting agencies, regional and state, generally recognize six factors in attempting to evaluate a junior college library, and they are all worth considering in evaluating the college library as well. These factors are: books, periodicals, staff, physical structure and equipment, finances or expenditures, and library use. Some of these are more important than others and some are based on others. Demonstrated weakness in some does not necessarily mean a poor library but weakness in all or most of them should certainly make one suspicious that the library is falling short of its obligation to the educational program. Evaluation in terms of these six factors can only indicate elements of strength or weakness but even this much is worth doing as a first step in planning for such improvements as may be feasible. The six elements which in sum go far toward defining the junior college and college library may now be considered. 
Books

Many of the accrediting agencies are quite arbitrary in defining the book content of the junior college. Kansas says there should be at least one thousand books, Tennessee specifies a minimum of eight thousand, and there are numerous variations in between. ${ }^{1}$ The standards adopted in 1932 by the Advisory Group on College Libraries of the Carnegie Corporation do not mention a definite number of books at all; Miss McCrum in her Estimate of Standards for a College Library cites figures ranging from 35,000 to 150,000 . The plain fact is that quantity as such is not a good measure of a library's quality. All that may be said is that the more books a library has, the better the chances that it will have the books it needs. The current trend in accreditation is to forego the quantitative criterion altogether, substituting the sensible, if vague, prescription that the collection be "adequate" or "useful" or "carefully selected." Such criteria are all intensely personal; they derive their meaning only in answer to an "in terms of." Thus a book collection is "useful" or "adequate" in terms of the demands imposed by the curriculum and teaching method of the particular college.

Since this is so, the college librarian wishing to ascertain how good his book collections are should consider them primarily in terms of the general educational and curricular program of his institution, and in general the best judges are the members of the faculty. No one member should be expected or entrusted to pass judgment on the collection as a whole, but each one is in a logically better position to

\footnotetext{
1 Junior college library standards cited throughout this paper are taken from the chart "Accreditation Requirements for Junior Colleges," which is based upon Eells, W. C. American Junior Colleges. American Council on Education, I940.
}

know something about the adequacy and quality of the library's collection in his specific field. In order to have an objective and workable basis for arriving at a decision, the following procedure has been used in some surveys, notably in the study of the Mount Holyoke College Library. ${ }^{2}$

\section{Available Book Lists}

There are now available several comprehensive book lists compiled with the general aim of providing a buying list for college and junior college libraries. The Shaw and Mohrhardt lists are the best known and they are especially useful because they are arranged to conform to the broad subject divisions into which the curricular organization normally falls. It should be remembered that these lists are essentially suggestive, and not prescriptive, buying lists; the titles included are not "musts" for any library and therefore the arbitrary use of these lists as evaluating instruments is to be questioned. But this is not to deny their usefulness in undertaking an evaluation. Either list, or preferably a combination of both, together with several additional lists, should be checked against the catalog of the library to show which of the listed titles are actually held. A faculty member should then be given the list pertaining to his subject specialization and he should be asked to consider the titles listed but not held by the library. He should judge each title for its value to his particular department and he might well indicate those "highly important," others "less important but desirable," the remainder to be left unmarked. It is to be hoped that his judgment will be influenced by the actual

\footnotetext{
of the Book Collection." "Evaluating the Adequacy braries 2:305-13, Sept. 1940. See also McCrum, op. cit., 1 24-27.
} 
holdings as well as gaps but even if he does no more than indicate the relative importance for his department of the listed titles he will have made available to the librarian a potential buying list arranged in a rough scheme of priorities. By-products of this procedure will at once occur to the librarian; for example, the faculty members will become acquainted with actual holdings and their attention will be called to titles once remembered but since forgotten; however, the principal consideration is that the procedure will serve as a basis for developing the collection with relevance to the curriculum of the college and the methods by which the content is presented.

\section{Use of Lists}

A few cautions should be noted with respect to the use of lists. As every librarian knows, book lists and bibliographies lose their currency within a very short time. This is particularly important because of the speed with which a more recent publication is substituted for an earlier book on the same subject. The recent book may not be better, but if the faculty member prefers it he should have an opportunity to indicate that preference in checking the list. In other words, the use of Shaw or Mohrhardt (or both) should be supplemented by lists or titles published subsequent to the issue of those valuable aids. Secondly, the lists should be used by sections and those sections not represented in the curriculum should be largely ignored. A library which contains few of the Shaw listings in astronomy is not unduly handicapped if astronomy is not included in the curriculum. ${ }^{3}$

\footnotetext{
${ }^{3}$ I am here considering one aspect of the book collection only: its function as supplementing the college curriculum, by far its most important. This, of course, is not to say that the book collection should not have books in astronomy or that it should be limited only to the curricular requirements.
}

In the third place, a standard list may represent inadequately certain aspects of the curriculum which are highly important in one institution and altogether ignored in others. This is likely to be particularly true in the case of institutions supported by religious groups. A Catholic institution, for example, cannot be evaluated fairly by the Shaw list, because its unique characteristic is altogether ignored by this list. In short, the list, or the section of the list, which is used must be relevant to the specific nature of the curriculum.

Finally, checking any list against library contents indicates lacks much better than it does actual holdings. Holdings are revealed only in so far as they also appear on the checklist. The checklist permits one to identify titles not held but it is possible that the library possesses other titles quite as good or even better. All of these qualifications are serious but they are not serious enough to militate against the essential soundness of the self-appraisal method suggested. No evaluation can be reduced to a set of rigid rules and procedures and the intelligence and judgment of the librarian should at all times be invoked to guard against a course which may inadequately take into account the shortcomings in the procedure itself.

\section{Periodicals}

As with book collections, so with periodicals one finds little agreement on the number to which a junior college library should subscribe. Minnesota advocates "two or three representing scientific or research activity" in each subject field; Tennessee requires "at least seventy-five appropriate to academic, cultural, and professional needs of the students." Miss $\mathrm{McCrum}$ reported wide variations among 
the college libraries; the average numbers of periodicals received in the small, medium-size, and large colleges were, respectively, 370, 650, and "well over I0oo." Clearly, the major consideration must be the relevance of the periodical collection to the aims of the curriculum and therefore essentially the same technique for appraising the book collection may be applied to the periodical collection. For periodicals the task is of course much simpler, because the possibilities are soon exhausted. In any subject field the number of periodicals extant is definitely limited. If the titles suggrested for any given field in, say, the Shaw and Mohrhardt lists and in the LyleTrumper list be combined, it is probable that the list will be quite satisfactory for the use intended. This list may then be checked by the librarian to indicate titles currently received and subsequently by the faculty member to suggest periodicals to which the library should subscribe, as well as to pass judgment on the merit of the subscription list within his field of specialization. It is assumed that this checking will be done, as with the checking of the book lists, with the particular needs of the curriculum in mind.

\section{Staff}

The requirement most frequently specified for a library staff is the common sense one that it be "competent." Along with this, however, one finds the conventional transition from competence as a desirable end in itself to professional training, which can be nothing more than a means to that end. In a word, wherever "professional training" is specified, there is the tacit assumption that it is this which makes for competence.

There are in fact two assumptions in- volved in the expectation that training and competence are causally related, assumptions which no analyst of a staff can avoid. The first is that the possession of professional training is sufficient to make for competence; given professional training, competence will follow. Is this true? The second is that unless one has had professional training one cannot be competent in the operation of the college library. Is this true? Merely to state the assumptions in this way is to imply that the answers must always be conditional. Every librarian knows that professional training is no categorical guarantee of competence and illustrations are abundant which testify to thorough competence in spite of the absence of professional training. This is not the place to analyze why this is so, nor its implications, beyond pointing out that in the last analysis the correct answer must be given in terms of the end-product rather than in terms of an assumed means to the achievement of that end. This means simply that a staff, or the individual members of a staff, are good or not to the extent that they do their specific jobs satisfactorily. It is no virtue in a staff member to be conversant with three or four foreign languages if his job requires nothing more than competence in his native tongue. Similarly, neither highly specialized bibliographical competence nor knowledge of the most advanced principles of library administration is relevant to the performance of routine library operations. It may perhaps be deplored that such abilities are not taken advantage of but this is beside the point. The proper measure of an individual's competence is the skill with which he performs his daily work. His other abilities are important only if they contribute to his work. 


\section{Evaluating a Staff}

So the problem of evaluating a staff is at once perhaps the most difficult and among the simplest in determining its contribution to library quality. Most difficult in the sense that the evaluation must be based on the nature of the job and this is frequently difficult to comprehend or to analyze in the sense of preparing a catalog of activities; most simple, in that the actual daily performance of the individual is clearly evident and ability as well as its opposite is clearly established. Indeed, no one can so well know how competent a staff is as the members themselves.

One further point. Unless the individual is considered specifically in relation to his job, there is the danger that he may be unduly praised or undeservedly condemned because of certain factors which are altogether beyond his control. A library with an excellent book collection and a large staff may extend excellent service simply because it does not suffer under financial handicaps and indeed possibly because it has so much money available that inefficiencies (unless they be too glaring) do not show up. It is relatively easy to be a "good" librarian when there is plenty of money for books and staff. On the other hand, a librarian may be unjustly blamed because a pinched library budget militates against adequate book stock and personnel, thus resulting in unsatisfactory service. Here certain praiseworthy qualities in a librarian may be ignored because of unavoidable general inefficiency. In neither case is the librarian's true quality revealed. Although finance has been selected for illustration, others may be substituted: faculty interest in developing the library and faculty stimulation of student use, and factors of a predominantly local character.

\section{Physical Structure and Equipment}

When the accrediting agencies set up standards for the junior college library building they employ such terminology as "sufficient space;" "facilities to make educational progress effective;" "well-lighted, fireproof ;" "adequately housed." The standards adopted by the Advisory Group on College Libraries included similar factors; the building should be designed for expansion, it should have sufficient space for storage, carrels in the stacks, etc. All of this is good common sense, though the factors named are frequently so vague that a subjective estimate is about the most one may expect. Even the provisions for rating college buildings now being formulated by a committee of the A.L.A. mention such common sense factors as a functionally central location, provision for expansion, adequate physical facilities, and efficient arrangement of working spaces, and leave their rating to the personal judgment of the librarian.

But just as handsome buildings and a nicely landscaped campus bear little relation to the quality of an educational institution, so the niceties of physical structure and equipment of a library have little to do with its essential excellence. A modern library building will not atone for a weak book collection and an outmoded building may dim but it will hardly eclipse the educational utility of a strong collection and competent staff. This is not to imply, of course, that a satisfactory building is irrelevant to the ability of a library to perform its functions well; it is merely to underscore the obvious fact that physical structure as such is a matter of secondary importance and should therefore not be given undue weight in any appraisal of library quality. 


\section{Library Use}

Public library standards usually specify a circulation of so many books per capita of population served or registered but junior college standards disregard a precise quantitative prescription altogether. Instead, the requirement if given simply asks that evidence of library use be shown or that a record of library use be kept, or, most vague of all, that use by faculty and students be "considered."

Paradoxically, though use of the library is perhaps the most important single aspect of a college library's operation, responsibility for that use is not the library's except in a relatively minor degree. Whether the library is much or little used will be found to be most closely related to the nature and requirements of the curriculum, to the method of teaching adopted by the faculty, and to the degree to which the faculty stimulate or encourage reading. Specifically "library" factors will operate in only a secondary capacity to affect the extent of library use and two of these have already been considered. Thus a poor book stock may militate against wide use and an inconvenient location will certainly not encourage it; in addition, onerous regulations, regardless of their necessity, may serve to diminish student use of the library.

In short, consideration of use as such will throw little light on library quality; even a "good" library may be but little used. However, where the library is used to too limited an extent the librarian may question whether such limitation is due to factors over which he has some control. In short, much or little use will not in itself indicate library quality but evidence of use should be related to underlying causes. Whether or not anything can be done or need be done to increase use where it appears to be unduly small will depend on the nature of these causes. Obviously many of them will be beyond the librarian's influence but should they be in any respect related to the management of the library itself, he should certainly be alert to effect such changes as are feasible.

\section{Library Finance}

The amount of money a library receives will certainly affect the number of books purchased and the personnel employed. Liberal support will not guarantee a good library but a niggardly budget will go far to prevent one. Nevertheless, the library's budget is not a good index to a library's quality; since it is always a means to a good library and never an end in itself, it can never answer whether a library is good or not, though it will obviously have much to say concerning the reasons for its quality or mediocrity.

There are no "oughts" about college library finance; no one can say how much a library ought to receive, any more than one can say how much faculty salaries should be or what the buildings and grounds department is entitled to. How much a library will actually get depends on numerous local factors; two in particular will probably determine the amount to a greater extent than any factor externally applied. These are, first, the total income of the institution, and second, the sum total of demands made upon it. Just as in public affairs "the claim of public libraries for public support is only relative to the valid claims of other functional agencies" ${ }^{4}$ so in academic institutions the library's claim for a part of the budget is relative to the demands of other.parts of

Leland, Simeon E. "Observations on Financing
Libraries." The Library Quarterly $2: 348$, Oct. 1932. 
the program. It is unrealistic to say the library should receive a definite amount without considering how much is available altogether or how much the teaching and administrative program is entitled to receive.

\section{Not Enough Money}

At the same time it is not unreasonable to hold that unless a library receives enough to enable it to do its job, the job probably won't be done or at best it won't be satisfactorily done. In the light of the unique character of every junior and liberal arts college, it is impossible to say how much is "enough." Therefore such quantitative standards as libraries are required to meet are essentially arbitrary, with little claim to universal acceptability. They are of three general kinds. First, a definite amount is specified as a minimal appropriation for books, regardless of size of student body, faculty, teaching method, or curriculum. This ranges for junior colleges from $\$ 400$ (Arkansas) to $\$ 800$ (West Virginia). Second, a certain amount is specified "per student," \$2.50 in some cases, $\$ 5.00$ in others. This approach, too, fails to take into consideration the nature of the curriculum and the teaching method; it also assumes that size of enrolment should determine library expenditures, rather than the necessities of the curriculum itself. The third type of financial standard assumes a constant relationship between educational activities and the library; therefore the library should receive a specific percentage of the total educational expenditure. In Nebraska this is given as 3 per cent. At least two criticisms may be made of this procedure: first, the assumption on which it is based-that a constant relationship should exist between these two factors-is highly questionable and is not even supported by logic; for increased expenditure for, say, the department of astronomy, which is likely to use the library relatively little, should not lead to an increased library appropriation. In the second place, the percentage suggested is simply a guess. All of these "standards" have the virtue of practicability; they are all easy to apply. Unfortunately, after the application has been made one is still at a loss to know whether the support which a library receives is actually "adequate". or not.

Because of the shortcomings of the conventional standards for finance, they should be applied with caution. It should be recognized that a library which performs well when measured by them is not necessarily, or by virtue of that fact, a good library, any more than a library showing up poorly on the financial "norms" is inevitably a poor library. At best, measurements of financial support may throw light on reasons for a library's quality; the measure of quality itself is derived more directly and logically from the book stock and personnel.

\section{Conclusion}

Six approaches to the measurement of a library's quality have now been presented. In the last analysis they may not answer the question "How good is my library?" but they will certainly help the librarian to know more about his library than he does now, and they may even suggest ways and means of removing shortcomings where they exist. At the very least they will prevent him from proceeding blindly in response to a vague conviction that something is wrong without knowing specifically what. 